ENTRE

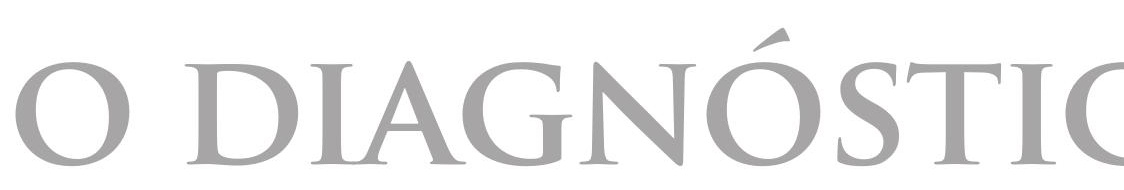
E A TERAPÊUTICA: AS VARIÁ NATURAIS NAS REPRESENTAC DO SUICÍDIO NOS JORI DE BELÉM DA PRIM DÉCADA DO SÉCUL 


\section{ENTRE O DIAGNÓSTICO}

E A TERAPÊUTICA: AS VARIÁVEIS NATURAIS NAS REPRESENTAÇÕES DO SUICÍDIO NOS JORNAIS DE BELÉM DA PRIMEIRA DÉCADA DO SÉCULO XX 


\title{
ENTRE O DIAGNÓSTICO E A TERAPÊUTICA: AS VARIÁVEIS NATURAIS NAS REPRESENTAÇÕES DO SUICÍDIO NOS JORNAIS DE BELÉM DA PRIMEIRA DÉCADA DO SÉCULO XX
}

\section{Resumo}

O artigo discute as representações das práticas suicidas em Belém do Pará, presentes nas notícias, nos artigos e nos anúncios publicados na imprensa belenense na primeira década do século XX. Em tais representações, observou-se a associação desse tema com os elementos da natureza em diversos sentidos e para fins variados. Positivados ou não, esses elementos se situavam entre a manutenção do instinto de autopreservação e a incitação da ideia de autodestruição, e que foram apropriados pelo discurso médico que então se firmava como definidor dos limites da normalidade, através de algumas instituições locais como a Sociedade Médico-Cirúrgica do Pará. Nesse contexto, o suicídio foi tratado no domínio das patologias humanas, enquanto se descortinavam múltiplas teorias médicas a respeito das causas e das profilaxias da considerada "mania suicida". O material impresso foi também confrontado com obras médicas produzidas ao longo dos trinta primeiros anos do século XX. Nessa análise, verificou-se que, até o discurso gerado fora do ambiente acadêmico da Medicina, como o religioso, valeu-se dos mesmos referenciais para argumentar contra o direito individual de dispor da própria vida.

Palavras-chave: suicídio, representação, Medicina, Belém do Pará.

\section{BETWEEN THE DIAGNOSIS AND THE THERAPEUTICS: NATURAL VARIABLES IN THE REPRESENTATIONS OF SUICIDE IN NEWSPAPERS OF BELÉM IN THE FIRST DECADE OF THE 2OTH CENTURY}

\begin{abstract}
This article discusses the representations of suicide in Belém do Pará in the news, articles, and advertisements published in Belém in the first decade of the 20th century. Suicide, as a subject, was noted to be intermeshed with elements of nature in different senses, and to different goals. Positive or not, these elements were in between the instinct of self-preservation and the incitement to the idea of self-destruction, which were appropriated by the medical discourse to define the limits of normalcy for some local institutions such as the Medical Surgical Society of Pará. In this context, suicide was treated as a human pathology, whereas multiple medical theories on the causes and the treatment of the so-called "suicidal mania" were produced. The research also compared newspapers articles and the medical works produced during the first 30 years of the 20th century. It was verified that even the discourse produced out of the academic millieu, e.g. the religious discourse, employed the same famework to argue against the individual right to decide about ones' own life.
\end{abstract}

Keywords: suicide, representation, Medicine, Belém do Pará. 


\section{ENTRE LE DIAGNOSTIC ET LA THERAPEUTIQUE: LES VARIABLES NATURELLES DANS LES REPRESENTATIONS DU SUICIDE AUX JOURNAUX DE BELEM PENDANT LA PREMIERE DECENNIE DU XX ${ }^{\text {EME }}$ SIÈCLE}

\section{Résumé}

Cet article traite des représentations du suicide dans la ville de Belém (état du Pará, au Brésil) véhiculées dans des nouvelles, articles et annonces publicitaires parus dans la presse locale pendant la première décennie du XXème siècle. Le thème du suicide y est associé aux éléments de la nature, en divers sens et différentes finalités. Pris en valeur ou non, ces éléments se situaient entre le maintien de instinct de conservation et l'incitation à l'idée d'autodestruction, qui s'étaient appropriés par le discours médical qui a ensuite stabilisé en définissant les limites de la normalité, à travers des institutions locales telles que la Sociedade Médico-Cirúrgica do Pará. Dans cette relation, le suicide a été classé dans le domaine des pathologies humaines, tandis que se développaient plusieurs théories médicales sur les causes et la prophylaxie de la " manie suicidaire". Confronté à la littérature médicale produite au long des trente premières années de la même période, même le discours religieux, produit en dehors du milieu académique de la médecine, a fait usage des mêmes référentiels pour argumenter contre le droit individuel de chacun de disposer de sa propre vie.

Mots-clés: suicide, representation, Médecine, Belém du Pará.

Endereço do autor para correspondência: Av. 16 de Novembro, $\mathrm{n}^{\circ}$ 627, apto.1403, Cidade Velha, Belém- PA-Brasil, CEP 66.023220. Email mctroy98@gmail.com 


\section{INTRODUÇÃO}

O tema da morte voluntária foi objeto de intensos debates na virada do século XIX para o XX, inclusive nas cidades brasileiras, entre as quais Belém do Pará. Seja em trabalhos acadêmicos, em obras jurídicas, ou mesmo nas inúmeras conferências em voga naquele período (Guimarães 2004), o suicídio não somente preocupava as autoridades religiosas, policiais e médicas, mas também a todos fascinava (Corbin 2003:591). Ao mesmo tempo, carregado de estigmas seculares, a sua face moderna se revelou nos avanços e nos recuos através das estatísticas sociais e dos processos de registro ao longo do século XIX, mensurada em números e em tabelas nos grandes centros urbanos do Ocidente (Semler 1998; Corbin 2003). O conjunto desses fatores contribuiu, de certo modo, para dar maior visibilidade ao tema e também despertar o debate público e científico a respeito do suicídio. Os saberes médico, jurídico e o ainda incipiente saber sociológico se debruçaram sobre esse fenômeno, dissecando-o como objeto de estudo em suas respectivas áreas.

Esse tamanho interesse pelo suicídio, na época, entretanto, não permite ao tempo presente afirmar que aquele período fosse um tempo de suicidas em Belém, por exemplo, em termos de maior número de casos ocorridos. Convém expor as razões e os problemas de ordem metodológica que se impõem nesse caso. A pesquisa privilegiou o uso de periódicos e de obras médicas de referência como fontes históricas, $\mathrm{O}$ que desautoriza chegar a tal constatação, para a qual se necessitaria de séries estatísticas regulares para um período constituído de relativa duração. Aliás, pode-se mesmo afirmar que trabalhar a historicidade da morte voluntária até meados do século XX, para os limites de uma cidade do porte de Belém do Pará, não seja tarefa das mais fáceis.

Nesse mesmo sentido, Susan Semler (1998:21) chega a afirmar que "a 'realidade’ histórica do suicídio (...) constitui terreno bastante escorregadio para o historiador". Acompanhando o tabu criado em torno do ato, as fontes documentais possíveis que lhe dizem respeito podem se restringir. Como assinala o historiador francês Georges Minois (1999:7) - especialmente para os períodos anteriores ao século XIX -, os arquivos judiciais se mostram "fragmentários" e escassos, ao passo que os registros paroquiais praticamente silenciam quanto à morte de suicidas, por interditos de ordem moral e religiosa. Semler (1998:20) talvez toque no ponto central do problema, que parece se aplicar ao caso específico de Belém do Pará no período estudado: sendo "tabu supremo da civilização ocidental", os sobreviventes do ato ${ }^{1}$ - parentes e amigos - procuram ocultar da vista da sociedade a sua prática. Assim, a escamoteação da verdadeira causa mortis se revela mais que uma hipótese. Alain Corbin (2003:593) se mostrou cético quanto ao crédito a ser dado aos depoimentos de familiares ou à palavra final das autoridades na França do século XIX a respeito do tema; "tendem a adocicar os fatos, manipulam os testemunhos, suprimem as fontes". Da mesma forma, o historiador Peter Gay (2001:215) per- 
cebeu o quanto as estatísticas de época podiam ser "equivocadas e fragmentárias", o quanto os critérios adotados para "distinguir a morte deliberada da acidental" podiam ser "inadequados", ou mesmo o quanto a ação policial podia ser incompetente, constituindo "obstáculos formidáveis" para a precisão dos estudos sobre suicídio.

O suicídio também é um ato de acentuado sentido privado, de forma que não se pode contar com muitos traços diretos deixados por seus autores, já que as célebres cartas de despedida se tornaram "parte do ritual de autodestruição" somente a partir de meados do século XIX, com o aumento dos índices de alfabetização e a valorização de certa sensibilidade romântica voltada à valorização do individual (Semler 1998:20). Ainda no caso relativo à Belém do início do século XX, os processos judiciais ou de investigação policial se mostram em quantidade diminuta, ${ }^{2}$ enquanto que as estatísticas oficiais, construídas e preservadas de modo fragmentado, evidenciam a tendência das autoridades públicas locais de subnotificarem os casos de suicídios ocorridos na capital paraense. $^{3}$

Por outro lado, a frequência com que o suicídio era tratado, nesse mesmo período, em textos legislativos, filosóficos, teológicos e de caráter científico, e até nas páginas diárias dos jornais, permite avaliar o quanto o tema exercia seu fascínio, seja pelas posições polêmicas que provocava, seja pelo interesse dos saberes médico, jurídico e sociológico em diagnosticá-lo e tratá-lo enquanto problema, seja pela exploração de seu caráter sensacional. A morte voluntária não deixou de ser tema de trabalhos acadêmicos, obras de referência, e até mesmo de artigos, de editoriais e de notícias publicadas nas folhas diárias dos centros urbanos do início do século XX, como em Belém do Pará. Semler (1998:56) observa que os jornais "constituíam o principal veículo de familiarização do suicídio aos olhos do público". Os periódicos procuravam, em textos narrativos, muitas vezes construídos da forma como hoje se entende por sensacionalista, manter o diálogo com todos aqueles saberes quanto ao trato sobre o suicídio, de modo que acabou por se constituir em fonte privilegiada de pesquisa. Contudo, convém ressalvar que a opção pelo uso dos jornais como fonte privilegiada, para o estudo do suicídio, não se deu exclusivamente por essas razões de ordem metodológica, como se fontes residuais fossem, ou seja, as que restaram para se trabalhar. Antes, deve-se reconhecer a riqueza e o valor do material contido nesses textos impressos nos jornais, especialmente no campo das representações do suicídio, e que se colocam à disposição para pesquisas que se abrem a novas perspectivas e possibilidades.

Pode-se afirmar que as práticas suicidas tiveram presença marcante no cotidiano dos leitores de periódicos diários do início do século XX, em cidades como Belém. As notícias sobre suicídio eram publicadas ao lado de outros fatos sensacionais ou bizarros, principalmente nos jornais noticiosos 
e cotidianos de circulação diária, com tal regularidade que o cônego Andrade Pinheiro 4 (1908:1) considerou, em editorial assinado para A Província do Pará de 23 de maio de 1908, que "a plebe ignara, e os levianos, e mais os sizudos a falarem na rua, nas casas, nas familias, por toda a parte, que a moda [do suicídio] pegou".

Enquanto as folhas diárias dos jornais de Belém na primeira década do século XX dialogavam com tradições filosóficas e com os debates jurídicos e médicos (clínicos e legais) sobre a morte voluntária, tais referências se faziam presentes nos editoriais, nos artigos (assinados ou não), nas notícias sobre o cotidiano, nas peças literárias (dispostas, ou não, em folhetins) e até nos anúncios comerciais de produtos e de serviços. Entre o uso humorístico do tema do suicídio, característica típica de jornais locais como O Binóculo (18961908), ou mesmo comercial, como nos anúncios de drogas e de elixires, o suicídio se mostrava recorrente e chamativo nas notícias - extensas, curtas ou mesmo telegráficas -, divulgando, em muitos casos, com riqueza de detalhes e de melodrama, as práticas suicidas (atos consumados ou tentativas) ocorridas em Belém, no interior do Estado e até em outros locais do Brasil e do mundo. Em qualquer espaço disponível na diagramação dos jornais, pode-se deparar com essas informações e discursos diretos sobre o suicídio, ou mesmo referências indiretas a ele, nos mais variados tons e com os mais diversos sentidos e significados: da defesa à condenação.

\section{CIVILIZAÇÃO VERSUS NATUREZA: O DEBATE EM TORNO DO SUICÍDIO NA IMPRENSA BELENENSE DO INÍCIO DO SÉCULO XX}

Em 24 de março de 1905, a Folha do Norte publicou, em primeira página, extenso artigo denominado $A$ morte do futuro. Esse título se mostra dúbio, no sentido de que pode dizer respeito tanto a uma crítica das práticas suicidas na cidade - que poderia levar ao fim da sociedade -, como a uma não menos provável apologia ao próprio suicídio. Nesse último caso, tal artigo iria de encontro às representações ocidentais comuns da morte voluntária à época. Segundo Peter Gay (2001:214), o suicídio podia ser considerado tanto como produto de "desarranjos mentais", quanto como forma de delinquência, "enquanto problema social". Sob o pseudônimo P." (1905:1), o articulista da Folha do Norte procurou afastar do suicídio qualquer sentido de covardia ou de culpa e reivindicar o direito individual de decidir sobre a própria morte, demonstrando a lógica racional que haveria por trás do ato suicida, ao retomar o debate iluminista do século XVIII (Minois 1998) em torno da descriminalização do ato: "Se é lícito ao caminhante sobreonerado com um peso superior ás suas forças, egualal-o ao seu esforço, alijando o excesso da carga que o opprime, porque não ha de ser permittido tambem aos infelizes, aos que não podem mais [sic], abreviar e anniquilar a vida que lhes pertence?"

Atualizando o discurso sobre a impossibilidade de ser feliz em tempos dos prodígios tecnológicos produzidos 
pelo progresso, P. (1905:1) considerava que "a felicidade corre adeante delle [do ser humano] com uma velocidade de que não ha simile na terra" ou que "são de aço inquebravel [sic] os grilhões da cadeia que nos escravisa". Nesse jogo com as referências de época - da rapidez dos meios de comunicação e de transporte ao material utilizado nas construções públicas (Schwarcz \& Costa 2000) - o artigo também ironizava o combate ao suicídio, situado no âmbito dos distúrbios mentais, pelas autoridades médicas e higienistas: " $\mathrm{O}$ que hoje é o resultado de uma allucinação será amanhã, talvez, o fructo da maior sensatez, o corollario logico do trabalho da razão agindo tranquillamente". Indo além, P. pretendia eternizar o suicídio para as gerações futuras enquanto modelo mais prático e racional de morte: "resta apenas que o homem saiba escolher o genero de suicídio que afaste a probabilidade do mais leve soffrimento...".

Em movimento oposto, A Província do Pará fez publicar, naquele editorial de 23 de maio de 1908, o artigo O Suicidio, da lavra do já citado cônego Andrade Pinheiro. O clérigo estava acostumado ao universo da palavra impressa dos jornais belenenses, tendo participado do corpo redacional de $A$ Boa Nova, jornal católico lançado em 1871 que se alinhava ao "discurso conservador da Cúria local” (Figueiredo 2005:249). Nesse artigo, Andrade Pinheiro (1908:1) reafirmava a oposição tradicional do catolicismo à morte voluntária, situando-a na condição simultânea de pecado e de crime:" "A mesma conscien- cia publica tanto sente e reconhece a monstruosidade do facto perante Deus e os homens (...) que não ha pedir para o suicida as preces e os suffragios da Egreja". Entretanto, Andrade Pinheiro foi além dos aspectos morais e teológicos que tradicionalmente nortearam o discurso eclesiástico sobre o tema do suicídio. Como fora assumido por ele, procurou estabelecer a condenação do suicídio sob o "ponto de vista natural, social e civilizador", embora situasse a onipotência divina no plano físico.

"O que é contra a natureza é sempre mau e reprovado" (Pinheiro 1908:1). Partindo dessa premissa, Andrade Pinheiro representou o suicídio como um câncer a ser extirpado da sociedade, e buscou no elemento selvagem, no ambiente da floresta - em contraposição ao civilizador da cidade -, a referência maior para a obediência às leis naturais que ter-se-ia perdido no processo civilizador. Paradoxalmente, com o intuito de salvar a civilização da sua própria autodestruição pelo suicídio: "ainda não ouvimos dizer que os selvagens se suicidem lá pelas brenhas, onde vivem isolados do convivio social".

Assim, o padre questionava se poderia ser considerada adiantada uma sociedade que tolerava o suicídio, fazendo duras críticas ao fato de a civilização ter produzido a sua própria porção de barbárie, que não seria permitida nem tolerada mesmo por "esses filhos das selvas". Percebe-se que Andrade Pinheiro confrontava certas representações em que o suicídio era tomado como o melhor índice medidor da civilização, pois justamente estaria em de- 
sacordo com o mais bestial dos instintos: o da autopreservação (Alvarez 1999: 69), construídas a partir de dados estatísticos que demonstravam o alto índice de suicídios nas principais capitais europeias.

Não foram apenas o intervalo de aproximadamente três anos, as perspectivas assumidas e os jornais diferentes - Folha do Norte e A Província do Pará - que distanciavam os artigos escritos pelo misterioso P. e pelo cônego Andrade Pinheiro. O primeiro articulista usou os requintes da civilização para defender a sua tese em favor do suicídio, e também argumentou pelos aspectos morais, com reminiscências às idéias filosóficas iluministas, apregoando o uso da razão. O sacerdote, por sua vez, buscou o mundo natural e retornou ao estágio julgado primitivo da humanidade, para perceber, no domínio $\mathrm{da}$ irracionalidade, a recuperação da autopreservação no cumprimento às leis naturais: "Se nos entes irracionaes, se nos bichos das mattas, ha o natural instincto da conservação (...), como é que o homem não apprende esta lição dos entes, cujos destinos são tão inferiores aos seus?!..." (Pinheiro 1908:1). Numa atitude que não deixa de ser antropocêntrica, Andrade Pinheiro colocou os humanos em condição vergonhosa no aprendizado edificante que se deveria obter, a seu ver, com tal exemplo dos animais. Essa foi uma posição diferente daquelas tomadas na modernidade clássica inglesa, tal como identificadas pelo historiador britânico Keith Thomas (1988:46). No artigo de Andrade Pinheiro, o suicídio não foi bestializado, mas sim represen- tado como produto da corrupção do instinto de preservação naturalmente atribuído a todas as criaturas, incluindo o homem.

A representação de que o processo civilizatório também acarretou atitudes irracionais - como a proliferação dos vícios, ou a tolerância para com o suicídio -, pode ser verificada em obras médicas editadas ainda nas décadas de 1920 e de 1930. No Ceará, Florival Seraine (1936:15) considerava - com base em estatísticas e em outros estudos (muitas vezes de casos estrangeiros) -, que "as classes mais ilustradas e os povos mais cultos contribuem com maior soma á morte voluntaria (...) a própria civilização é apontada como determinante do fenômeno". Por outro lado, denunciando a oferta dos vícios (como o álcool) e a vida estressante nos populosos centros urbanos, também observava que a classe proletária era outra vítima desse "Molóque autocída" (Seraine 1936:17).

O cônego Andrade Pinheiro finalizou seu artigo com o temor da influência das próprias notícias impressas acerca do suicídio sobre o modo de agir dos leitores. Como já citado anteriormente, o padre se preocupava com o estabelecimento de certo modismo das práticas suicidas provocado pelas notícias sobre o assunto veiculadas nos jornais, como espécie de atualização dos temores do século XIX quanto às ondas de suicídios que se seguiam a partir da leitura de textos literários. " "Tempo houve em que a imprensa tomára o alvitre de não contar os casos de suicidio (...) depois mudou de pensar, e agora 
conta-os a reportagem arguta até pormenorizada!" (Pinheiro 1908:1).

Em seu artigo de 1908, o cônego Andrade Pinheiro se antecipava ao verdadeiro debate local travado dez anos depois entre a imprensa e as instituições ligadas ao saber médico-científico belenense. $\mathrm{O}$ saber e discurso médicos, por sinal, firmavam-se como legitimadores para definir os contornos da normalidade e ditar as regras de conduta nas cidades brasileiras (Lopes 1998). Em janeiro de 1918, a Sociedade Médico-Cirúrgica do Pará - que havia sido inaugurada em 15 de agosto de 1914 -, colocou as notícias de sensação sobre crimes (dentre os quais incluíam os casos de suicídio) na relação de suas preocupações higienistas. Essa associação fez publicar, em jornais como Estado do Pará (de 18 de janeiro de 1918) e a Folha do Norte (de 22 de janeiro de 1918), proposta deliberada em sua assembléia, para que a Associação da Imprensa do Pará se empenhasse em conseguir junto aos noticiaristas dos jornais "a modificação no relato [pormenorizado] dos mesmos factos [criminais], que continuando a ser feito pela forma actual, vem attentar contra os mais comezinhos principios de prophylaxia social". Havia, portanto, o temor de certo segmento social, representante do discurso médico, para com a veiculação de certas notícias que, escritas especialmente na forma de fait divers, ${ }^{10}$ pudessem levar o seu leitor a determinadas práticas, ou seja, conduzi-lo à imitação do ato narrado em função de alegada sugestão.

O saber médico e científico chegou a classificar determinadas leituras - colocando-as no âmbito das práticas con- denáveis -, pela simples razão do conteúdo do que se lia. Em Belém do Pará, o médico Castro Valente (1919:7), respaldando-se em séries estatísticas produzidas por psiquiatras e por criminologistas (todas estrangeiras), procurava extrair do leitor a confirmação para a pergunta que, em si, já era uma afirmação: "as notícias dos jornaes sobre (...) suicidios (...) já não foram, ha muito condemnadas pelos psychologos e sociologos como nocivas e anti-hygienicas á saude espiritual dos leitores?". Anos mais tarde no Ceará, Seraine (1936:45) lançaria críticas ainda mais contundentes às notícias de suicídio impressas nos jornais, relacionando-as à representação que ele mesmo fazia de quem seria seu público leitor: o povo, que passaria a ser indiferente a notícias desse tipo, na formação do que seria um péssimo hábito de leitura. Considerações dessa ordem eram a expressão acabada de um saber que exercia coerção sobre as práticas de leitura, e que as procurava limitar, desautorizar, ou mesmo enquadrar enquanto perniciosas.

Desse modo, convém ainda notar que, no citado artigo de Andrade Pinheiro, mesmo o saber eclesiástico se valeu de termos e de argumentos não propriamente respaldados no mundo sobrenatural e em bases morais. $\mathrm{O}$ apelo à razão e ao que era tido por natural em muito aproximava a escrita do cônego à do saber científico. Assim, percebe-se a instituição desse saber o médico em especial - que ganhava corpo na sociedade e espaço nos jornais: a sua apropriação nos artigos e 
nas notícias servia como legitimador do próprio discurso perante os leitores (Lopes 2007:88). O suicídio chegou redefinido, no início do século XX, "como exemplo de patologia”, o que o ligava a outras questões, afastando-o da esfera de reflexão do estigma moral, "na medida em que implicaram debates sobre julgamentos éticos, entendimento científico e políticas sociais” (Gay 2001:212).

\section{SOB AS INFLUÊNCIAS DOS CÉUS, DA TERRA, DAS ÁGUAS E DA HEREDITARIEDADE: AS VARIÁVEIS NATURAIS UTILIZADAS NAS REPRESENTAÇÕES MÉDICO- CIENTÍFICAS DO SUICÍDIO}

O gradual processo de intervenção higienista na sociedade, em especial nas cidades, ao longo do século XIX, levou o saber médico a uma "presença e visibilidade na esfera pública” e que se inseria "em uma disputa por uma disciplinarização, normalização e até mesmo adestramento da população urbana" (Lopes 1998:40). O tema da morte voluntária não deixou de ser analisado nesse aspecto, e a sua divulgação nos periódicos sofreu, de certo modo, a influência desse saber médicocientífico. Partia-se do princípio de que o suicídio se associava ao universo dos distúrbios mentais, enquanto deliberação interna da pessoa.

A forma como as notícias de jornais em Belém se referiam às práticas suicidas respaldava-se nas terminologias próprias empregadas pela medicina (clínica e legal), "segundo a qual o suicida era o doente, o louco, o de- sesperado..." (Lopes 1998:20). Títulos como victima do alcool (d'A Província do Pará de 16 de junho de 1908) e Uma desventura emocionante - louca por amôr (da Folha do Norte de 14 de junho de 1901) colocavam-se ao lado das chamadas já comuns Um desgraçado que se mata ( $\mathrm{da}$ Folha do Norte de 13 de julho de 1900). São, sobretudo, representações em que se demarcavam campos possíveis de existência e de discussão do suicídio.

O discurso médico associava a prática suicida a várias causas ocasionais ou predisponentes, seja por loucura, por paixões (também doentias), ou mesmo por condutas desviantes, mas também pela vontade consciente e refletida do seu autor. $\mathrm{Na}$ década de 1930, consideravam que "nem todo o individuo que procura a morte pode ser taxado de anormal" (Seraine 1936:9). Enquanto que as causas poderiam ter o marcado sentido de patologia, de degeneração da espécie, e em que, inclusive, percebemse as variáveis naturais sendo também consideradas, caberia ao saber médico definir os limites da normalidade nos suicídios, e estabelecer parâmetros pelos quais se poderia atribuir a culpa e a própria responsabilidade do suicida (Lopes 2007), a partir da alegação de o mesmo estar, ou não, sob efeito de distúrbios mentais. Segundo Peter Gay (2001:214), “o diagnóstico do suicídio como o mais desesperado recurso da doença mental entrou em moda por volta de meados do século [XIX] e abriu a porta para esforços humanitários de prevenção".

Ainda na primeira metade do século XIX, médicos, como o cirurgião inglês 
Forbes Winslow, atribuíam o aumento nos casos de suicídio, dentre outros, à "umidade atmosférica", contra os quais prescreveu métodos terapêuticos envolvendo "banhos frios e laxantes" (Alvarez 1999:211). Até mesmo o próprio contato do homem com o ambiente natural, ou melhor, o seu estranhamento frente às formas grandiosas da natureza, podiam evocar o pensamento de autodestruição, dada a sensibilidade do sujeito. $\mathrm{O}$ general Couto de Magalhães ${ }^{11}$ (1998:126) teceu considerações nesse sentido, acerca da região serrana do Rio de Janeiro (em especial Petrópolis), conforme notas de seu diário de outubro de 1880: "aquelas serras abruptas e estéreis, aqueles precipícios escuros, trazem a idéia constante do suicídio". Já no século XX, ao que parece, a relação entre os fatores climáticos (e outras condições ambientais) com a vontade de morrer perdeu muito da sua força. $\mathrm{O}$ acadêmico baiano Quintino Costa (1927:9-10) apenas se reportava a estudos anteriores, reproduzindo a tese de que as "temperaturas extremas têm sido incriminadas de despertarem nos individuos certas tendencias ao crime, como ao suicidio" que os tornam "aptos a receberem suggestões psychicas, alimental-as e executal-as". Já Seraine (1936:11) considerava que o clima desempenhava apenas "papel adjuvante na gênese do ato", respaldando-se em resultados contraditórios obtidos por métodos estatísticos.

Entretanto, na Belém do início do século XX, certa representação da loucura e do suicídio nos jornais locais indica que ainda perdurava a crença de que fatores climáticos podiam agravar estados mentais já alterados. Em 13 de dezembro de 1907, a Folha do Norte publicou, em primeira página, a então tentativa de suicídio do português (residente em Belém) Armindo Ferreira Brandão por meio da ingestão de sublimado corrosivo. ${ }^{12}$ Tendo sido acometido de perturbação mental no início daquele ano, Arlindo Brandão havia viajado à terra natal para recolhimento no hospital Passos Ferreira, na cidade do Porto. Em novembro de 1907, regressara a Belém após sentir certas melhoras. Porém "com a mudança do clima, aggravou-selhe o estado de saude, sendo, por vezes, trahido pela memoria, pois que o enfraquecimento cerebral accentuava-se-lhe cada vez mais". ${ }^{13}$

No caso do português suicida, entretanto, a umidade equatorial típica de Belém não teria agido sozinha sobre a sua mente. Outro elemento importante presente em tais notícias sobre suicídio é a preocupação em demonstrar as possíveis formas de transmissão de tais "sinistros designios". Nesse caso, a hereditariedade mórbida, conceito que se refinou e se difundiu ao longo do século XIX (Corbin 2003), serviu como viés explicativo para o irromper da loucura, como a predisposição inoculada no indivíduo, a brotar na ocorrência de qualquer causa determinante ou mesmo ocasional. O temor constante dessa degeneração latente, desse "fundo de perversidade oculto” (Gay 1990:140), perpassa muitas das notícias de jornais sobre suicídio ou loucura na Belém do início do século XX. Nelas, a noção de 
"família patológica", empregada por Alain Corbin (2003:565) para a sensibilidade burguesa e francesa do século XIX, encaixa-se à perfeição. Um dado noticiado (que não pode passar despercebido) quanto à qualidade genética de Armindo Brandão, por exemplo, dava conta de que "varias pessoas de sua familia tinham já fallecido com o espírito envolvido nas densas trevas da loucura e outras se acham ainda acorrentadas ao peso desse infortunio". ${ }^{14}$

A noção de indivíduo predisponente ao suicídio ainda se faz presente em obras de referência médica décadas depois. Porém a herança patológica passou a dividir terreno com a idéia do contágio. Como afirmou Seraine (1936:35): "para que se verifique o contágio é necessário [sic] a existencia de um terreno especial, 'mais ainda que aptidão: espécie de estado latente"'. Ou mesmo perde seu significado: Quintino da Costa (1927:8), por exemplo, descarta a possibilidade de o fator hereditário ter papel decisivo nas questões da alma: "uma propriedade da alma, do espírito, não é entretanto transmissível pela gestação". ${ }^{15}$

Se a loucura e o suicídio poderiam estar relacionados ao princípio da degeneração latente, outras teorias argumentavam razões mais práticas, porém ainda internas ao corpo das pessoas, e que eram apropriadas pelos jornais para fins comerciais. Os anúncios de vendas de fármacos e dos produtos de uso doméstico eram tão generalizados que chegavam a ocupar as últimas folhas dos jornais diários de Belém no início do século XX. Segundo Sant'Anna
(1997:100), tais anúncios são bons indicativos para se perceber as "exigências sociais" da época, pincipalmente no tocante aos cuidados com o corpo. Nesse sentido, observa-se a importância dada aos remédios na vida cotidiana da cidade, apresentados na perspectiva de estabelecerem a linha que separava o estado de saúde do de desespero e, a depender da proposta, que separava a vida da morte ou da própria vontade de se matar. Até nesses anúncios, percebe-se a apropriação da ideia de suicídio, direta ou indiretamente, como também, a sua associação ao funcionamento de determinados órgãos e sistemas do corpo humano.

Afora a mais evidente associação do suicídio com disfunções do sistema nervoso, havia também a sua vinculação ao funcionamento gástricointestinal, dentre as várias linhas, precocemente abertas, de diagnósticos médicos. Alain Corbin (2003:570) identificou, em alguns tratados médicos franceses do século XIX, relações estabelecidas entre os distúrbios gástricos e a então nebulosa psique feminina: "outros clínicos, mais pudicos, atribuem a clorose ao mau funcionamento do estômago, equivalente simbólico do útero". Em anúncios impressos na Folha do Norte e n'O Jornal do primeiro semestre de 1905, como os da água industrializada Superaris, foi representada a relação do aparelho digestivo com as doenças da alma, e com a ideia de suicídio em particular.

Com o sugestivo título de Combate ao suicidio, anunciavam-se as propriedades medicinais desse produto de mesa que, 
sem rodeios, arrogava-se da eficácia em acabar com semelhante "crime de lesa humanidade". A linha argumentativa de tais anúncios era apropriada à pequena dimensão do espaço ocupado nas folhas dos jornais, mas não deixava de se respaldar nas teorias médicas utilizando as terminologias que lhes eram próprias - que a legitimavam enquanto discurso. Considerando que "todo o suicida é um dyspeptico acompanhado da dilatação do estomago ou das gastralgias", 16 argumentava-se, nesses anúncios, que o aumento de tamanho desses órgãos prejudicava o regular funcionamento dos outros órgãos vizinhos, como o coração e o fígado, trazendo-lhes sérias lesões. $\mathrm{Na}$ sequência, ao dispéptico acarretaria uma série de males e de maus pensamentos que "lhe abate o moral e atrophia a intelligencia, apagando o maior instincto nato do homem - o da conservação". ${ }^{17}$ Em parte, o anúncio tocava no ponto atacado pelo cônego Andrade Pinheiro em seu artigo de 1908, no que se referia ao instinto da preservação da espécie. Bastaria ao doente, portanto, ter a sua digestão facilitada para acabar com esse mal, para o que se recomendava beber a água Superaris "antes, durante e depois das refeições", ou misturá-la ao leite, ao refresco de frutas ou ao xarope. ${ }^{18}$

É interessante notar que os anúncios da água Superaris não se faziam inéditos no quadro das propagandas impressas nos jornais da época. Por outro lado, faltam elementos mais seguros para afirmar que se tratasse de certa tradição na apropriação do tema da morte voluntária, como estratégia de venda de artigos os mais diversos. O certo é que, n'A Província do Pará de 19 de maio de 1899, publicou-se, em segunda página, anúncio bem mais modesto a respeito, mas não menos interessante que o veiculado em 1905. Associando também as indisposições provocadas por distúrbios no sistema digestivo às ideias de suicídio, o Licor Paraense - produzido pela firma Rodrigues Vidigal \& C. ${ }^{a}-$, propunha-se também como meio mais eficaz de combater o suicídio, bastando apenas tomar um vidro do elixir para salvar o suicida irremediavelmente do mal que o acometia. Nesse caso, o suicida seria todo aquele que sofre de "febres palustres, perniciosas, sezões e inflammação do figado e baço". ${ }^{19}$

Nas teses acadêmicas e em outras obras médicas de referência, observam-se propostas profiláticas e terapêuticas de contenção do suicídio bem mais elaboradas do que sugerir a simples ingestão de água, de licores ou se servir de outros expedientes os mais prosaicos. Há tempos, mais acentuadamente a partir do século XIX, no imaginário ocidental, que o ambiente rural se contrapunha física e moralmente ao urbano, mais especificamente à superpopulação, à vida agitada e à insalubridade deste: as virtudes do campo versus os vícios da cidade. "Em parte, essa convicção se devia à deterioração do ambiente urbano" (Thomas 1988:291). Pode-se observar também que correspondia a certa "convenção clássica" de que os habitantes daquele ambiente rural “eram não apenas mais saudáveis, 
porém moralmente mais admiráveis que os habitantes da cidade" (op.cit.:293).

Como já visto, a própria civilização era percebida enquanto encorajadora do aumento nos casos de suicídio. Segundo Peter Gay (2001:215), a sociedade industrial era vista aos olhos dos cientistas já do século XIX como "um viveiro de desorganizações pessoais, das quais o suicídio era apenas o sintoma mais dramático". Portanto, o deslocamento do doente para outro ambiente, fora do centro urbano no qual vivia, mesmo que seja para o retorno à sua terra natal, fazia parte da terapêutica. Há de se lembrar que, na notícia que divulgou o suicídio de Armindo Brandão, este vinha de uma estadia em um hospital de Portugal.

O recolhimento asilar dos diagnosticados loucos se consolida a partir do século XIX, com os estabelecimentos das clínicas e dos centros de internação (Corbin 2003). Porém, paralelamente a esse aspecto da intervenção médica, aprimorou-se "uma medicina natural despertada por um projeto ecológico ainda pouco explícito" (Corbin 2003:599), voltando-se o olhar terapêutico para o cultivo do tempo livre, e o deslocamento e isolamento no campo.

Como se observa nas obras de Quintino da Costa e de Florival Seraine (nas décadas de 1920 e de 1930), havia toda a preocupação em disciplinar o corpo e os hábitos cotidianos para prevenir - ou, ao menos, retardar - o despertar da mania suicida inoculada nos predispostos. Segundo Peter Gay (2001:216), atribuía-se, como causa principal dos índices crescentes de suicídio, o de- clínio da moralidade com a gradual institucionalização do secularismo. $\mathrm{Ou}$ seja, fica patente como toda essa terapêutica visava garantir, acima de tudo, certa moral julgada em perigo, e que se colocava em alternativa aos tratamentos médicos convencionais por meio do isolamento, da vigilância constante, da dieta apropriada, dos banhos prolongados, do tratamento medicamentoso por meio de drogas produzidas, e até mesmo da incipiente intervenção psicanalítica (Seraine 1936).

Nesse sentido, também se empregaram as variáveis naturais. Ao lado do fortalecimento da instrução moral, das uniões estáveis e legalizadas, e da propaganda contra o alcoolismo e outros vícios (Seraine 1936), prescreveram-se, em especial, a higiene corporal, o exercício físico regulado, além do contato direto com a natureza. $O$ sentido estava em garantir a "relativa robustez nervosa" e o "maior vigor de energia psíquica” (Seraine 1936:61). O tempo livre destinado ao repouso também fazia parte desse receituário, ao mesmo tempo em que se também aconselhava distrair os "tarados por hereditariedade" com ocupações, passeios, exercícios e leituras selecionadas que lhe concentrassem as energias (Seraine 1936: 66-67). Na atenção especial que o mundo ocidental passou a dedicar ao corpo, e ainda dentro da esfera médica ao final do século XIX, Alain Corbin (2003:611) notou que "a medicina natural (...) preconiza o passeio pelo campo, a excursão à montanha, mais tarde os banhos de mar e de bicicleta". Como também analisara Glaura Lima 
(2006:243) - no estudo das estâncias hidrominerais que se proliferaram a partir da década de 1930 no Brasil: "aliada aos fatores climáticos, a variação de lugar, alterando hábitos ou incorporando outros, tornava-se vital ao alívio do ritmo em crescente tensão nos centros urbanos".

\section{CONSIDERAÇÕES FINAIS}

Pode-se perceber, através dos anúncios, das notícias e dos artigos publicados na imprensa belenense do início do século XX, como o suicídio se fazia cotidiano na cidade como objeto de leitura. O debate sobre o direito ou sobre o dever de viver tinha, como alguns de seus pontos de referência, o instinto de preservação e o uso da razão. Nas mais diversas representações sobre a morte voluntária, visualizavam-se o embate entre a cidade (de Belém) e a floresta que a rodeava; entre o mundo natural e o artificial; entre o selvagem e a civilização, em campos opostos e ambíguos. $\mathrm{Na}$ atração ou no distanciamento desses pólos, movimenta-se o fio da vida, cutucado pela ideia do suicídio, que poderia se fazer latente ou transmissível como gérmen, segundo concepções de ordem médica que reverberavam no seio da sociedade. Onde estaria a origem do mal? Algumas teorias científicas apontavam para a própria natureza, mais precisamente para o seu mau funcionamento. Do recôndito do interior da mente humana, havia outra natureza ainda nebulosa, mas passível de ser dissecada e classificada, e que mobilizava o saber médico - o psiquiátrico, em particular.
Enquanto isso, os jornais se encarregavam de levar ao grande público leitor de Belém esse saber em fragmentos, no gosto diário de uma notícia de sensação ou de uma polêmica aberta. $\mathrm{E}$ as variáveis naturais também foram apropriadas nesses discursos, entre o diagnóstico e a terapêutica, na crença de que, na natureza, residem tanto o princípio da vida como o da morte.

\section{NOTAS}

1 O termo "sobreviventes" é usado neste artigo, mesmo que anacrônico em relação ao período trabalhado, para designar as pessoas com quem o suicida se relacionava em vida e as testemunhas do ato suicida. Termo aplicado nas discussões psiquiátricas contemporâneas sobre o suicídio em relação ao processo de "elaboração do luto" após a morte do suicida (Cassorla 1998:23-24).

${ }^{2}$ O Centro de Memória da Amazônia, espaço de pesquisa em História em Belém do Pará mantido pelo convênio entre a Universidade Federal do Pará e o Tribunal de Justiça do Estado do Pará, conta com apenas cinco inquéritos policiais sobre práticas de suicídio para os anos iniciais do século XX (1901 a 1903).

3 As próprias estatísticas oficiais, presentes nos poucos números disponíveis do Boletim mensal de estatística demógrafo-sanitária da cidade de Belém - depositados no setor de Obras Raras da Biblioteca Pública ArthurVianna, da Fundação Cultural do Pará Tancredo Neves, e compreendendo, de modo fragmentado, o período de 1896 a 1911 - evidenciam a intenção governamental de escamotear a ocorrência de suicídios na capital paraense no período: estes se relacionavam a algumas mortes descritas nas relações de exames cadavéricos e autópsias presentes nesses boletins, mas que não configuravam nos números finais, espe- 
cificamente de óbitos causados por suicídios, presentes nas tabelas de mortalidade que também constavam em tais documentos oficiais.

${ }^{4}$ Pode-se situar o cônego Andrade Pinheiro, sacerdote da Sé de Belém e diretor do Colégio São José, como agente local do movimento reformista da romanização, operado em terras paraenses a partir da segunda metade do século XIX, e que visava a aproximação maior com o pontificado romano, por meio de uma "ideologia extremamente conservadora” (Maués 1994).

${ }^{5}$ É possível que o pseudônimo P. se refira ao jornalista Paulo Maranhão (João Paulo de Albuquerque Maranhão), que mais tarde se tornaria o diretor-proprietário da Folha do Norte e um dos fundadores da Academia Paraense de Letras (Rego 2005).

${ }^{6}$ Nessa passagem do artigo $A$ morte do futuro, há vagas referências à parte do romance epistolar Julia ou A nova Heloísa, do filósofo e escritor genebrês Jean Jacques Rousseau (17121778; ver Rosseau 1994), em que, no debate sobre o suicídio, representou os sofrimentos da vida como incômodo, ou como relação de desvantagem entre a força e o peso do fardo.

${ }^{7}$ Com mais ênfase a partir da doutrina de Santo Agostinho (século IV), e dos sucessivos concílios, como os de Orléans (ano 533), de Braga (ano 562), e de Toledo (ano 693), foram se incorporando ao direito canônico as medidas repressivas contra o suicídio e a série de restrições e punições impostas ao corpo dos suicidas e a seus descendentes (Alvarez 1999:80-81).

${ }^{8}$ Refere-se, particularmente, à obra de Johann Wolfgang Goethe, Os sofrimentos do jovem Werther (1774), a quem lhe atribui a grande causa da onda de suicídio na Europa Central oitocentista a partir da Prússia (Alvarez 1999:206-208).

9 "Sociedade Médico-Cirurgica". Estado do Pará, 18 de janeiro de 1918, página 2.

${ }^{10}$ Segundo Marlise Meyer (1996:94), fait divers é o termo francês utilizado para designar o "relato romanceado do cotidiano real", mas com grande fundo moral. A pretensa descrição objetiva do fato se mescla à inventividade do articulista para tornar o grotesco e o extraordinário elementos narrativos de atração do grande público: a leitura descompromissada.

${ }^{11}$ O general do Império José Vieira Couto de Magalhães, mineiro e considerado herói da Guerra do Paraguai, chegou a ser presidente da província do Pará durante os anos de 1864 a 1866.

12 Armindo Brandão viria a falecer dias após, conforme noticiado pela Folha do Norte de 17 de dezembro de 1907, em decorrência do veneno ingerido. Segundo o Diccionario de medicina popular e das sciencias acessórias... (Chernoviz 1890), obtinham-se as pastilhas de sublimados corrosivos da combinação entre as substâncias químicas cloro e mercúrio.

13 “Os Desesperados da Vida." Folha do Norte, 13 de dezembro, página 1.

${ }^{14}$ Op.cit.

${ }^{15}$ Deve-se registrar que o acadêmico Quintino Castellar da Costa se manifestou, favoravelmente, à doutrina espírita em sua tese, citando termos próprios como "encarnação" ou "espírito obssessor", associando loucura com possessão, e mesmo transcrevendo mensagens psicografadas como elementos válidos para defender sua argumentação. Dessa filiação religiosa, certamente provem seu posicionamento quanto à separação entre espírito e corpo.

16 "A morte do futuro." Folha do Norte, 24 de março, página 2 .

$$
\begin{aligned}
& { }^{17} \text { Op.cit. } \\
& { }^{18} \text { Op. cit. } \\
& { }^{19} \text { A Província do Pará, 1899:2. }
\end{aligned}
$$




\section{REFERÊNCIAS}

Alvarez, A. 1999. O deus selvagem: um estudo do suicídio. São Paulo: Companhia das Letras.

Cassorla, R. M. S. 1998. Considerações sobre o suicídio, in Do suicídio: Estudos brasileiros, pp.17-26. Campinas: Papirus.

Chernoviz, P. L.N. 1890. Sublimado, in Diccionario de medicina popular e das sciencias acessorias para uso das familias..., vol.2, p.1014. Paris: A. Roger e F. Chernoviz.

Corbin, A. 2003. Gritos e cochichos, in História da Vida Privada: da Revolução Francesa à Primeira Guerra vol.4. Organizado por M. Perrot, pp. 563-611. São Paulo: Companhia das Letras.

Costa, Q. C. da. 1927. Do suicidio e sua prophylaxia. Tese de Doutorado. Faculdade de Medicina da Bahia, Salvador, Brasil.

Figueiredo, A. M. de. 2005. Páginas antigas: uma introdução à leitura dos jornais paraenses, 1822-1922. Margens. Revista Multidisciplinar do Núcleo de Pesquisas CUBT/ UFPA 2(3): 245-66.

Gay, P. 1990. A experiência burguesa da rainha Vitória a Freud: a paixão terna. Vol. 2. São Paulo: Companhia das Letras.

2001. A experiência burguesa da rainha Vitória a Frend: o cultivo do ódio. Vol. 3. São Paulo: Companhia das Letras.

Guimarães, V. dos S. 2004. Notícias diversas: suicídios por amor, 'leituras contagiosas' e cultura popular em São Paulo nos anos 10. Tese de Doutorado. Programa de Pós-graduação em História Social do Departamento de História da Faculdade de Filosofia, Letras e Ciências Humanas, Universidade de São Paulo.

Lima, G. T. N. 2006. O natural e o construído: a estação balneárea de Araxá nos anos 1920-1940. Revista Brasileira de História 26(5):227-250
Lopes, F. H. 1998. O suicídio sem fronteiras: Entre a razão e a desordem mental. Dissertação de Mestrado. Departamento de História do Instituto de Filosofia e Ciências Humanas, Universidade Estadual de Campinas.

Lopes, F. H. 2007. Suicídio \& saber médico: estratégias históricas de dominio, controle e intervenção no Brasil do século XIX. Rio de Janeiro: Ateliê.

Magalhães, J. V. C. de. 1998. Diário Íntimo. São Paulo: Companhia das Letras.

Maués, R. H. 1994. A categoria "jesuíta" no embate entre liberais e católicos ultramontanos no Pará do século XIX, in Anais do $19^{\circ}$ Encontro Anual da Associação Nacional de Pós-graduação e pesquisa em Ciências Sociais-ANPOCS. Caxambu, MG.

Meyer, M. 1996. Folhetim: uma história. São Paulo: Companhia das Letras.

Minois, G. 1998. História do suicídio: a sociedade ocidental perante a morte voluntária. Lisboa: Teorema.

Pinheiro, A. 1908. O suicidio, in A Provincia do Pará, 23 maio:1.

Rego, C. Ms. 2005. O labirinto do pseudônimo. Belém: Imprensa Oficial do Estado do Pará.

Rousseau, J.-J. 1994. Júlia on A nova Heloisa: cartas de dois amantes habitantes de uma cidadezinha ao pé dos Alpes. Campinas: Editora da Unicamp e HUCITEC.

Schwarcz, L. M., Â. M. da Costa. 2000. 1890-1914: no tempo das certezas. São Paulo: Companhia das Letras.

Semler, S. A. 1998. Uma Morte Privilegiada? Suicídio, história e literatura nos Estados Unidos no final do século XIX. Tese de Doutorado, Programa de Pós-graduação em História Social do Departamento de História da Faculdade de Filosofia, Letras e Ciências Humanas. Universidade de São Paulo. 
Carvalho, M. J. P.

Seraine, F. 1936. Considerações sobre o autocídio. Fortaleza: Ramos \& Pouchain.

Thomas, K. 1988. O bomem e o mundo natural: mudanças de atitude em relação às plantas $e$ aos animais, 1500-1800. São Paulo: Companhia das Letras.

Valente, C. 1919. Pyschiatria e Psychologia in Pará-Medico: Archivos da Sociedade Medico-Cirurgica do Pará 2(7):67-68.

Recebido em 16/01/2013.

Aprovado em 21/03/2013. 